\title{
Exploring the Immunopathogenesis of Viral Hemorrhagic Fever in Mice with a Humanized Immune System
}

\author{
Günther Schönrich* and Martin J. Raftery \\ Institute of Medical Virology, Charité - Universitätsmedizin Berlin, Berlin, Germany
}

Viral hemorrhagic fever (VHF) as a disease entity was first codified in the 1930s by soviet scientists investigating patients suffering from hantavirus infection. The group of hemorrhagic fever viruses (HFVs) has since expanded to include members from at least four different virus families: Arenaviridae, Bunyaviridae, Filoviridae, and Flaviviridae, all enveloped single-stranded RNA viruses. After infection, the natural hosts of HFVs do not develop symptoms, whereas humans can be severely affected. This observation and other evidence from experimental data suggest that the human immune system plays a crucial role in VHF pathogenesis. For this reason mice with a human immune system, referred to here as humanized mice (humice), are valuable tools that provide insight into disease mechanisms and allow for preclinical testing of novel vaccinations approaches as well as antiviral agents. In this article, we review the impact of humice in VHF research.

Keywords: viral hemorrhagic fever, humanized mice, mice with a humanized immune system, virus-induced immunopathogenesis, viruses

\section{INTRODUCTION}

Emerging viral hemorrhagic fever (VHF) refers to a group of distinct but similar zoonotic diseases induced by different enveloped RNA viruses. They cause increased vascular permeability that affects one or more organ systems and finally may result in life-threatening shock (1). Thrombocytopenia, another key symptom of VHF, can be due to either increased platelet destruction or decreased platelet production by megakaryocytes (2). Hemorrhagic fever viruses (HFVs) belong to four separate virus families: Flaviviridae, Bunyaviridae, Arenaviridae, and Filoviridae. Small mammals such as rodents and bats are the natural hosts, which are chronically infected without developing obvious symptoms. Humans are dead-end hosts that usually clear the virus after incidental infection but may develop acute symptoms.

Suitable animal models that reproduce key symptoms of VHF are rare (3-5). Non-human primates (NHPs) are the gold standard for some VHF types such as Ebola virus disease (EVD) but cannot be used for others such as dengue fever (DF) $(6,7)$. In addition, ethical and economic considerations clearly restrict research with NHPs. Guinea pigs or hamsters show typical symptoms after infection with some HFVs (8-10). However, the lack of species-specific immunological reagents complicates experiments. Laboratory mice often do not support replication of HFV or require the adaption of virus isolates to the mouse, thereby reducing their value as a model of human infection $(11,12)$.

The advent of humanized mice (humice) has opened up a new avenue for VHF research. In the 1980s, experiments demonstrated successful engraftment of human hematopoietic stem cells 
(HSCs) in immunodeficient mice (13). Today humice offer the opportunity to gain new and exciting insights into important human diseases such as cancer, allergies, and infections (14-17). Humice are an especially valuable test bed for HFVs. Firstly, HFVs specifically target human myeloid cells such as dendritic cells (DCs) (18-24). Secondly, evidence is accumulating that an inadequate immune response substantially contributes to VHF pathogenesis (25). This aspect is difficult to study in conventional animal models, as their immune system differs substantially due to evolution driven by exposure to different groups of pathogens over millions of years (26-28). For instance, there are major differences regarding the response of pattern recognition receptors to stimulation by invading pathogens. Although closely related to humans, even NHPs show interspecies immunological differences to humans $(29,30)$.

In this review, we summarize the novel insights gained from experiments with humice in VHF research.

\section{CATEGORIES OF HUMICE USED IN VHF RESEARCH}

The utility of immunodeficient mice as recipients of a human immune system has continuously increased. Efficient reconstitution with human hematopoietic cells was first described in non-obese diabetic (NOD)/severe combined immunodeficiency (SCID) mice $(31,32)$. The homozygous SCID mutation impairs murine $\mathrm{T}$ and $\mathrm{B}$ cell development, whereas the NOD background results in deficient natural killer $(\mathrm{NK})$ cell function. The Sirpa gene polymorphism in the NOD background also curtails phagocytosis of engrafted human HSCs (33). NOD/SCID mice have subsequently been improved by truncation or deletion of the murine IL-2 receptor common gamma (IL-2R $\gamma$ ) chain (34-36). This molecule represents an important component of the highaffinity receptors for several inflammatory cytokines. The NOD/ SCID/IL-2R $\gamma^{-/-}$(NSG) mice are thus severely deficient in innate immunity and show augmented human HSC engraftment. The reconstitution with human HSCs in NSG mice is long lasting (37). In another approach, the IL- $2 \mathrm{R} \gamma^{-/-}$mutation was introduced into mice with a mutated recombination activating gene 2 (Rag2) on a BALB/c background (38). The Rag2 mutation in these BALB/c Rag2-/-/IL-2R $\gamma^{-/-}$(BRG) mice renders them completely free of murine $\mathrm{T}$ and $\mathrm{B}$ cell cells, whereas the SCID mutation is "leaky," meaning that some functional murine $\mathrm{T}$ and B cells develop (39).

The different types of humice differ with regard to efficiency of human HSC engraftment and the resulting composition of human hematopoietic cells (40-42). In VHF research, mainly HSC-engrafted humice and bone marrow/liver/thymus (BLT) humice are used. In the HSC-engrafted humice, human $\mathrm{CD}_{3} 4^{+}$ HSCs from various sources (bone marrow, cord blood, peripheral blood or fetal liver) are inoculated into newborn immunodeficient mice and allowed to develop (Figure 1). A major disadvantage of HSC-engrafted humice is the lack of human T cell education due to the absence of a human thymus. This situation has been improved by generating transgenic NSG mice expressing human leukocyte antigen (HLA) molecules. Transgenic NSG mice expressing the HLA class I molecule HLA-A2 (hereafter referred to as NSG-A2 mice) facilitate the development of functional CD8 T cells after reconstitution with HLA-A2 $2^{+}$human HSCs (43-45). The expression of HLA class II molecules allows the development of both antibody-producing and class-switching human B cells (46-48).

The BLT humice enables human $\mathrm{T}$ cells to differentiate in an autologous human thymus $(49,50)$. BLT mice are generated by transplantation of human fetal liver and thymus tissue fragments under the kidney capsule of immunodeficient mice, e.g., NOD/SCID or NSG mice, followed by intravenous injection of autologous HSCs derived from fetal liver (Figure 1). The major advantage of BLT mice is their ability to mount a relatively effective human adaptive immune response due to the presence of a human thymic environment and the resultant HLA-restricted T cell repertoire. Caveats are the requirement of human fetal tissue and the relatively frequent development of graft-versus-host disease.

Elimination of human hematopoietic cells by murine phagocytic cells combined with defective human hematopoiesis in humice put a curb on human erythrocytes $(51,52)$, platelets $(53)$, neutrophils (54-56), monocytes/macrophages (57), and NK cells $(58,59)$. An explanation for defective human hematopoiesis is the lack of binding of important murine growth factors and cytokines to receptors on human progenitor cells. An elegant solution of this problem is the generation of homozygous knock-in mice to replace murine with human cytokines (60-63). Germlinecompetent ES cells from NSG mice have been established to facilitate their genetic modification (64). Recently, transgenic NSG mice have been developed that constitutively express human "myeloid" cytokines: human stem cell factor, human granulocyte/ macrophage colony-stimulating factor 2, and human IL-3. After reconstitution with human HSCs, these NSG-SGM3 mice allow better development of human myeloid cells, the key target cells of VHF viruses (65-68).

So far, four different HFVs from three virus families (Flaviviridae, Filoviridae, and Bunyaviridae) have been studied in humice.

\section{FLAVIVIRUSES}

Dengue viruses (DENVs) are the cause of the most important arthropod-borne viral disease in terms of global distribution and economic impact (69). The known DENV serotypes (DENV-1 to DENV-4) are members of the Flaviviridae family and carry a positive-sense single-stranded RNA genome. The Aedes aegypti mosquito, which is found in tropical and subtropical areas, functions as the main vector. Roughly 2.5 billion people, i.e., two fifths of mankind, live in endemic areas. An estimated 390 million people become infected per year. The most frequent clinical manifestation is DF, a self-limiting febrile disease with spontaneous recovery (70). However, some patients develop major complications such as plasma leakage leading to shock, respiratory distress, bleeding and organ impairment.

DF has been extensively studied in humice (Table 1). After DENV-2 infection, NOD/SCID mice and NSG mice develop fever, erythema, and human thrombocytopenia compatible to the human disease $(71-73)$. The decrease in human 


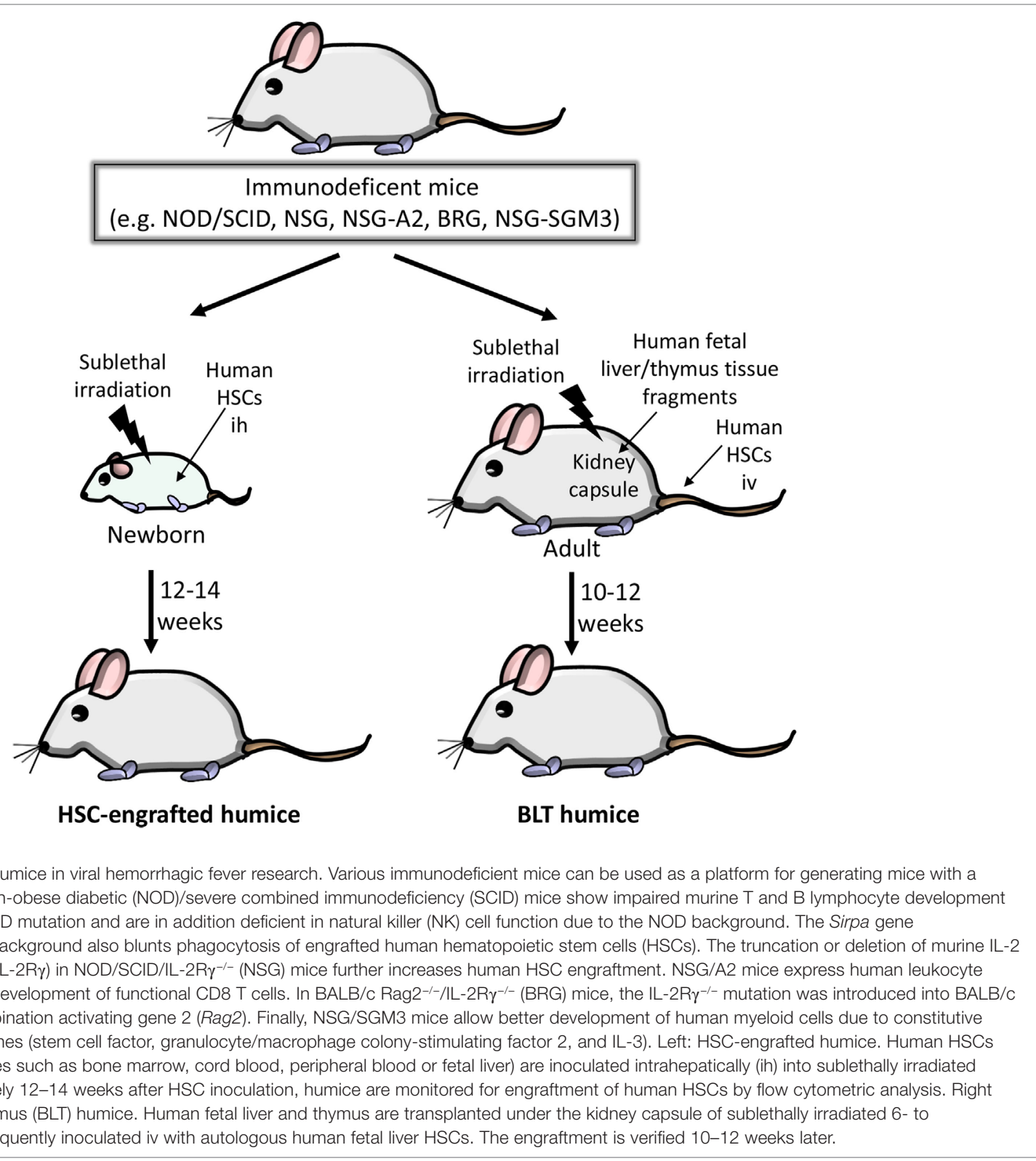

platelets is due to inhibition of human megakaryocyte development (74). DENV-2 could be detected in several human cell types in the bone marrow, spleen, and blood of these mice (73). In accordance, human cells isolated from the bone marrow of NSG mice were susceptible to DENV-2 infection in vitro (43). This cell tropism is in agreement with studies demonstrating DENV-derived protein in phagocytic cells in human autopsy tissue such as lymph nodes and spleen (75). Intriguingly, when infected Aedes aegypti transmitted DENV-2 to humice during feeding, more sustained and severe viremia, erythema and thrombocytopenia occurred compared to other modes of virus inoculation (76). This suggests that the mosquito bite itself and mosquito saliva contribute to dengue pathogenesis.

The immune system plays a crucial role in dengue pathogenesis $(25,77)$. Firstly, in humans, priming of the antiviral immune response with one DENV serotype often causes a more severe disease after infection with another DENV serotype at a later time point. Secondly, the most severe symptoms are observed at the peak of the human antiviral immune response. For these reasons the response of human immune cells has been studied in humice of DENV infection. Human anti-DENV IgM antibodies were detected 2 weeks after infection of BRG mice with DENV-2 followed by virus-reactive IgG at 6 weeks postinfection (78). In accordance, it was observed that NSG mice infected with DENV-2 through mosquito bite developed a virus-specific adaptive immune response (76). Moreover, human T cells from infected NSG-A2 mice secreted cytokines in response to known stimulatory HLA-A2-restricted DENV-2 peptides (43). Finally, NK cells are activated by contact with infected DCs before they control DENVs through IFN- $\gamma$ secretion (79). 
TABLE 1 | Humanized mouse models in viral hemorrhagic fever (VHF) research.

\begin{tabular}{|c|c|c|c|c|}
\hline Disease & Virus/family & Platform & Key findings & Reference \\
\hline DF & DENV-2/Flaviviridae & NOD/SCID, NSG & DF symptoms (fever, rash, and thrombocytopenia) & $(71,72)$ \\
\hline DF & DENV-2/Flaviviridae & NSG & DENV-2 tropism as in human DF & $(43,73)$ \\
\hline DF & DENV-2/Flaviviridae & NSG & Thrombocytopenia due to inhibition of megakaryocyte development & $(74)$ \\
\hline DF & DENV-2/Flaviviridae & NOD/SCID-BLT, NSG & $\begin{array}{l}\text { Effective DF treatment with adenosine nucleoside inhibitor or } \\
\text { therapeutic antibody }\end{array}$ & $(84,85)$ \\
\hline DF & DENV-2/Flaviviridae & NSG/A2 & Virus-specific HLA-A2-restricted human T cell response & $(43)$ \\
\hline DF & DENV-2/Flaviviridae & BRG, NSG, NSG/A2 & Virus-specific hulgG and hulgM response & $(43,76,78)$ \\
\hline DF & DENV-2/Flaviviridae & BLT-NSG & Serotype-cross-reactive hulgM antibodies with poor neutralizing activity & $(80,81)$ \\
\hline DF & DENV-2/Flaviviridae & NSG/SGM3-BLT & Higher levels of antigen-specific hulgM and hulgG compared to BLT-NSG & $(82)$ \\
\hline DF & DENV-2/Flaviviridae & NSG & Serum metabolomics similar to human DENV infections & (83) \\
\hline EVD & EBOV/Filoviridae & NSG-A2 & EVD symptoms (cell damage, liver steatosis, hemorrhage, high lethality) & (96) \\
\hline EVD & EBOV/Filoviridae & NSG-BLT & $\begin{array}{l}\text { Increased levels of pro-inflammatory cytokines and liver enzymes; } \\
\text { histopathological findings typical for EVD }\end{array}$ & (94) \\
\hline EVD & EBOV/Filoviridae & NSG-SGM3 & Absence of characteristic EVD histopathology & (95) \\
\hline $\mathrm{CCHF}$ & CCHFV/Bunyaviridae & NSG-SGM3 & Lethal disease with severe neuropathology (gliosis, meningitis, meningoencephalitis) & $(99)$ \\
\hline HFRS & HTNV/Bunyaviridae & NSG, NSG-A2 & $\begin{array}{l}\text { Highest numbers of HTNV copies in the lung, humanized NSG-A2 mice develop } \\
\text { faster and more severe symptoms such as thrombocytopenia }\end{array}$ & $(112)$ \\
\hline
\end{tabular}

BLT, bone marrow/liver/thymus model; BRG, BALB/c Rag2-/- IL-2R ${ }^{-1-}$ mice; CCHF, Crimean-Congo hemorrhagic fever; CCHFV, Crimean-Congo hemorrhagic fever virus; DENV-2, dengue virus serotype 2; DF, dengue fever; EBOV, Ebola virus; EVD, Ebola virus disease; HFRS, hemorrhagic fever with renal syndrome; HTNV, hantaan virus; NOD, non-obese diabetic mice; NSG, NOD/SCID/IL-2R $\gamma^{-/-}$mice; NSG-A2, NSG mice constitutively expressing HLA-A2; NSG-SGM3, NSG mice constitutively expressing human stem cell factor, human granulocyte/macrophage colony-stimulating factor 2, and human IL-3; SCID, severe combined immunodeficiency mice; HLA, human leukocyte antigen.

The virus-specific immune response has also been studied in DENV-2-infected NSG-BLT mice (80, 81). Human T cells isolated from NSG-BLT mice during acute infection and in the convalescence phase secreted IFN- $\gamma$ after stimulation with DENV-2 peptides (80). In addition, human B cells secreted DENV-2-reactive IgM antibodies (80). The majority of these antibodies were serotype cross-reactive, recognized epitopes on envelope proteins and intact virions, and neutralized poorly (81). The antibodies generated in the convalescence phase showed higher avidity compared to antibodies found in acute infection (81). Accordingly, NSG-BLT mice in the convalescence phase showed decreased virus titers after being challenged with a clinical DENV-2 strain. Furthermore, preincubation of DENV-2 virions with immune sera from immune NSG-BLT mice reduced viral replication after inoculation into naïve mice (81). In DENV-2-infected BLT mice generated from NSGSGM3 mice, improved B cell development and higher levels of antigen-specific IgM and IgG were observed compared to DENV-2-infected NSG-BLT mice (82). The serum metabolomics of DENV-2-infected humice is similar to human DENV infections demonstrating the utility of humice for analyzing DENV-associated pathogenesis (83). In addition, a therapeutic antibody and an antiviral drug were successfully tested in DENV-2-infected humice $(84,85)$. These studies emphasize the value of humice in translational and preclinical VHF research.

\section{FILOVIRUSES}

The dramatic 2014 outbreak of EVD in West Africa underlines the need to better understand this deadly disease (86). Ebola virus (EBOV) and Marburg virus, a closely related HFVs, belong to the Filoviridae family in the order Mononegavirales (87).
These large enveloped filamentous viruses are equipped with a negative-sense single-stranded RNA genome. Bats represent potential reservoirs for Marburg virus (88) and, more speculatively, perhaps also EBOV. They are persistently infected without showing symptoms and can spread the viruses to humans and NHPs. EVD has a high case fatality rate and affects many organs resulting in a variety of symptoms including gastrointestinal, respiratory, neurological, and vascular (89). Most impressive are the hemorrhagic manifestations such as petechiae, ecchymoses, and mucosal hemorrhages. The final and most severe stage of EBOV disease is characterized by shock, systemic impairment of coagulation and convulsions. The fatal outcome is most likely a consequence of both the direct effects of lytic EBOV replication and an inadequate immune response $(90,91)$. In EVD survivors, long-lasting activated CD8 T cells have been detected, suggesting that EBOV-derived stimulatory antigen persists at low levels within the organism (92).

Small animal models for analyzing filovirus pathogenesis have been generated using laboratory mice, guinea pigs, and the Syrian hamster (93). Recently, the potential of humice for modeling EBOV disease was explored in three different types of humice (Table 1) $(6,94-96)$. To this end, NSG-A2, NSG-SGM3, and NSG-BLT mice were infected with low-passage wild-type EBOV isolates. EBOV-infected NSG-A2 mice started to lose weight around day 7 postinfection and some hallmarks of human EBOV disease were observed including cell damage, liver steatosis, signs of hemorrhage, and high lethality (96). Intriguingly, there was a direct correlation between EBOV disease severity and the level of HSC engraftment. In contrast, unreconstituted NSG-A2 mice showed only mild symptoms with weight loss starting later in the third week postinfection and gradually continuing until the time of death around day 30 postinfection. NSG-A2 mice reconstituted with normal murine HSCs, another 
important control, survived EBOV infection. These results emphasize the importance of human hematopoietic cells for EVD pathogenesis.

In EBOV-infected NSG-BLT mice, clinical illness depended on viral dose inoculated and donor tissue used for reconstitution (94). Moderate leukopenia and thrombocytopenia and histopathological alterations similar to those found in human victims were observed. Liver enzymes and key pro-inflammatory human cytokines associated with fatal EVD (e.g., TNF- $\alpha$, IL-1, IL-6, and IL-10) were increased. In contrast, unreconstituted NSG control mice survived EBOV, underlining the role of human hematopoietic cells in EVD pathogenesis.

After EBOV infection of NSG-SGM3 mice, high virus titers were found in blood, liver, and spleen (95). Most of the mice died within 2 weeks of infection. In accordance with the concept that human myeloid cells spread VHF viruses within the organism, viral antigen was found in tissue-residing human macrophages and DCs and later in the course of infection also in murine parenchymal cells. In contrast to EBOV-infected NSG-A2 and NSG-BLT mice, the characteristic histopathology of severe human EBOV disease was not observed. This difference could be explained at least in part by the lack of HLA class I-restricted functional T cells in NSG-SGM3 mice. Thus, the lethal disease observed in these mice may be due to pathology directly induced by EBOV or due to innate immune responses.

\section{BUNYAVIRUSES}

A number of HFVs belong to the family Bunyaviridae. These are enveloped viruses that carry a genome consisting of three negative-sense single-stranded RNA segments (97). Recently, Crimean-Congo hemorrhagic fever virus (CCHFV) belonging to the genus Nairovirus and Hantaan virus (HTNV), the prototype member of the genus Hantavirus, have been analyzed in humice.

Crimean-Congo hemorrhagic fever $(\mathrm{CCHF})$ represents the most relevant tick-borne viral disease in humans due to its wide distribution. Sporadic cases or outbreaks of CCHF are observed in a vast geographic area including western China, the Middle East, southern Europe, and most parts of Africa (98). CCHFV circulates in wild and domestic vertebrates that are transiently infected without showing symptoms. Humans become infected through tick bite or contact with body fluids from infected patients or animals. As with other VHFs, the spectrum of symptoms of Crimean-Congo hemorrhagic fever includes mild fever, vascular leakage resulting in multiorgan failure, and finally shock with coagulation defects. Case fatality rates of up to $30 \%$ have been reported. A recent study analyzed CCHFV-infected NSG-SGM3 mice (Table 1) (99). They showed lethal disease resembling CCHF in some respects. CCHFV was detected in many organs including liver, spleen, and brain, similar to CCHFV-infected mice deficient in type I IFN responses. Histopathological analysis revealed several features typically found in CCHF such as the presence of viral antigen within Kupffer cells, endothelial cells, and hepatocytes. Similar to human CCHF cases, vacuolar degeneration/steatosis and increased single cell necrosis were observed. CCHV-infected humice also developed CNS symptoms such as meningitis and meningoencephalitis. Intriguingly, a population of activated human CD8 $\mathrm{T}$ cells was identified that could contribute to immunopathology or virus elimination in a non-specific (HLA class I-independent) way (99).

Hantaviruses are globally emerging pathogens responsible for VHF in Africa, America, Asia, and Europe (100). Rodents, shrews, moles, and bats serve as natural hosts for hantaviruses. In contrast to all other pathogenic members of the family Bunyaviridae, hantaviruses are transmitted to humans via aerosols derived from rodent excreta. Depending on the geographic region, hemorrhagic fever with renal syndrome (HFRS) or hantavirus cardiopulmonary syndrome (HCPS) may develop (101). Both types of disease bear pathogenic similarities with increased vascular permeability and loss of platelets as leading symptoms (102). Hantavirus replicate in cell culture without causing obvious cytopathic phenomena, suggesting that immune mechanisms play a role in HFRS/HCPS $(103,104)$. In line with this view, the susceptibility to hantavirus infection and the clinical course of hantavirus-induced disease in humans are linked to polymorphisms of immune-related genes (105). Moreover, pathogenic hantaviruses infect human myeloid cells such as DCs and monocytes and interact with neutrophils, the most abundant immune cells $(21,23,106-109)$. This tropism may help the pathogens to spread within the organism. In addition, this may also result in an inadequate immune response such as the excessive release of neutrophil extracellular traps that damages the endothelial barrier $(110,111)$.

Recently, hantaviral pathology was analyzed in HTNVinfected NSG mice and NSG-A2 (Table 1) (112). In both types of humice, hantaviral genomic RNA was detected in the kidney, liver, and spleen, but the highest viral copy numbers were found in the lung. Significant weight loss occurred earlier in NSG-A2 mice (day 10) than in NSG mice (day 15). HTNV-infected unreconstituted NSG mice that served as a control showed only a slight but not significant weight loss within the observation period. Inflammatory infiltrates in the lung of HTNV-infected NSG-A2 mice were stronger than in NSG mice. Similarly, the number of human platelets dropped significantly in NSG-A2 mice, whereas the observed reduction in NSG mice was not significant. Although hantaviruses infect human megakaryocytic cells, they do not cause alterations in cell survival or differentiation (113). Thus, it is likely that hantavirus-induced thrombocytopenia is due to increased platelet destruction (114). Taken together, these findings indicate that human hematopoietic cells including HLA-A2 restricted human $\mathrm{T}$ cells play a pivotal role in hantaviral pathogenesis.

\section{CONCLUSION AND FUTURE DIRECTIONS}

Humice are an extremely useful but still not optimal tool for elucidating the mechanisms of VHF immunopathogenesis, in particular, because of the very limited range of alternative research models. In addition, humice facilitate testing of vaccines and novel antiviral agents (115). Development of these 
therapeutic agents is urgently needed for treatment and prevention of highly lethal VHFs. For example, humice can be used to generate human monoclonal antibodies for VHF prophylaxis (116). Finally, standardized humice allow the prospective testing of newly discovered HFVs or viruses suspected to be potentially HFVs and could form part of a zoonosis threat detection network. Future attempts have to improve the utility of humice as VHF models by further allowing better engraftment and differentiation of HSCs as well as the development of a fully functional lymphoid tissue architecture that efficiently supports human immune reactions.

\section{REFERENCES}

1. Paessler S, Walker DH. Pathogenesis of the viral hemorrhagic fevers. Annu Rev Pathol (2013) 8:411-40. doi:10.1146/annurev-pathol-020712-164041

2. Schönrich G, Raftery MJ. Megakaryocytes and platelet production during viral infection. In: Schulze H, Italiano J, editors. Molecular and Cellular Biology of Platelet Formation. Switzerland: Springer (2016). p. 351-62.

3. Falzarano D, Bente DA. Animal models for viral haemorrhagic fever. Clin Microbiol Infect (2015). doi:10.1111/1469-0691.12630

4. Gowen BB, Holbrook MR. Animal models of highly pathogenic RNA viral infections: hemorrhagic fever viruses. Antiviral Res (2008) 78(1):79-90. doi:10.1016/j.antiviral.2007.10.002

5. Smith DR, Holbrook MR, Gowen BB. Animal models of viral hemorrhagic fever. Antiviral Res (2014) 112:59-79. doi:10.1016/j.antiviral.2014.10.001

6. Prescott J, Feldmann H. Humanized mice - a neoteric animal disease model for Ebola virus? J Infect Dis (2016) 213(5):691-3. doi:10.1093/infdis/ jiv539

7. Zellweger RM, Shresta S. Mouse models to study dengue virus immunology and pathogenesis. Front Immunol (2014) 5:151. doi:10.3389/fimmu. 2014.00151

8. Connolly BM, Steele KE, Davis KJ, Geisbert TW, Kell WM, Jaax NK, et al. Pathogenesis of experimental Ebola virus infection in guinea pigs. J Infect Dis (1999) 179(Suppl 1):S203-17. doi:10.1086/514305

9. Ebihara H, Zivcec M, Gardner D, Falzarano D, LaCasse R, Rosenke R, et al. A Syrian golden hamster model recapitulating ebola hemorrhagic fever. J Infect Dis (2013) 207(2):306-18. doi:10.1093/infdis/jis626

10. Hooper JW, Larsen T, Custer DM, Schmaljohn CS. A lethal disease model for hantavirus pulmonary syndrome. Virology (2001) 289(1):6-14. doi:10.1006/ viro.2001.1133

11. Ebihara H, Takada A, Kobasa D, Jones S, Neumann G, Theriault S, et al. Molecular determinants of Ebola virus virulence in mice. PLoS Pathog (2006) 2(7):e73. doi:10.1371/journal.ppat.0020073

12. Valmas C, Basler CF. Marburg virus VP40 antagonizes interferon signaling in a species-specific manner. J Virol (2011) 85(9):4309-17. doi:10.1128/ JVI.02575-10

13. Kamel-Reid S, Dick JE. Engraftment of immune-deficient mice with human hematopoietic stem cells. Science (1988) 242(4886):1706-9. doi:10.1126/ science. 2904703

14. Akkina R. New generation humanized mice for virus research: comparative aspects and future prospects. Virology (2013) 435(1):14-28. doi:10.1016/ j.virol.2012.10.007

15. Ernst W. Humanized mice in infectious diseases. Comp Immunol Microbiol Infect Dis (2016) 49:29-38. doi:10.1016/j.cimid.2016.08.006

16. Fujiwara S. Humanized mice: a brief overview on their diverse applications in biomedical research. J Cell Physiol (2017). doi:10.1002/jcp.26022

17. Walsh NC, Kenney LL, Jangalwe S, Aryee KE, Greiner DL, Brehm MA, et al. Humanized mouse models of clinical disease. Annu Rev Pathol (2017) 12:187-215. doi:10.1146/annurev-pathol-052016-100332

18. Bosio CM, Aman MJ, Grogan C, Hogan R, Ruthel G, Negley D, et al. Ebola and Marburg viruses replicate in monocyte-derived dendritic cells without inducing the production of cytokines and full maturation. J Infect Dis (2003) 188(11):1630-8. doi:10.1086/379199

\section{AUTHOR CONTRIBUTIONS}

Both authors contributed to the conception, writing, and critical revising of this review.

\section{FUNDING}

This work was supported by Deutsche Forschungsgemeinschaft (support code SCHO/9-1) and by the Bundesministerium für Bildung und Forschung (ERA-Net/GALHANT; support code 01DJ6022).

19. Geisbert TW, Hensley LE, Larsen T, Young HA, Reed DS, Geisbert JB, et al. Pathogenesis of Ebola hemorrhagic fever in cynomolgus macaques: evidence that dendritic cells are early and sustained targets of infection. Am J Pathol (2003) 163(6):2347-70. doi:10.1016/S0002-9440(10)63591-2

20. Mahanty S, Hutchinson K, Agarwal S, McRae M, Rollin PE, Pulendran B. Cutting edge: impairment of dendritic cells and adaptive immunity by Ebola and Lassa viruses. J Immunol (2003) 170(6):2797-801. doi:10.4049/ jimmunol.170.6.2797

21. Marsac D, Garcia S, Fournet A, Aguirre A, Pino K, Ferres M, et al. Infection of human monocyte-derived dendritic cells by ANDES Hantavirus enhances pro-inflammatory state, the secretion of active MMP-9 and indirectly enhances endothelial permeability. Virol J (2011) 8:223. doi:10.1186/ 1743-422X-8-223

22. Negrotto S, Mena HA, Ure AE, Jaquenod De Giusti C, Bollati-Fogolin M, Vermeulen EM, et al. Human plasmacytoid dendritic cells elicited different responses after infection with pathogenic and nonpathogenic Junin virus strains. J Virol (2015) 89(14):7409-13. doi:10.1128/JVI.01014-15

23. Raftery MJ, Kraus AA, Ulrich R, Kruger DH, Schonrich G. Hantavirus infection of dendritic cells. J Virol (2002) 76(21):10724-33. doi:10.1128/JVI.76.21.10724-10733.2002

24. Wu SJ, Grouard-Vogel G, Sun W, Mascola JR, Brachtel E, Putvatana R, et al. Human skin Langerhans cells are targets of dengue virus infection. Nat Med (2000) 6(7):816-20. doi:10.1038/77553

25. Screaton G, Mongkolsapaya J, Yacoub S, Roberts C. New insights into the immunopathology and control of dengue virus infection. Nat Rev Immunol (2015) 15(12):745-59. doi:10.1038/nri3916

26. Barreiro LB, Quintana-Murci L. From evolutionary genetics to human immunology: how selection shapes host defence genes. Nat Rev Genet (2010) 11(1):17-30. doi: $10.1038 / \mathrm{nrg} 2698$

27. Mestas J, Hughes CC. Of mice and not men: differences between mouse and human immunology. J Immunol (2004) 172(5):2731-8. doi:10.4049/ jimmunol.172.5.2731

28. Zschaler J, Schlorke D, Arnhold J. Differences in innate immune response between man and mouse. Crit Rev Immunol (2014) 34(5):433-54. doi:10.1615/ CritRevImmunol.2014011600

29. Barreiro LB, Marioni JC, Blekhman R, Stephens M, Gilad Y. Functional comparison of innate immune signaling pathways in primates. PLoS Genet (2010) 6(12):e1001249. doi:10.1371/journal.pgen.1001249

30. Magalhaes I, Vudattu NK, Ahmed RK, Kuhlmann-Berenzon S, Ngo Y, Sizemore DR, et al. High content cellular immune profiling reveals differences between rhesus monkeys and men. Immunology (2010) 131(1):128-40. doi:10.1111/j.1365-2567.2010.03284.x

31. Hesselton RM, Greiner DL, Mordes JP, Rajan TV, Sullivan JL, Shultz LD. High levels of human peripheral blood mononuclear cell engraftment and enhanced susceptibility to human immunodeficiency virus type 1 infection in NOD/LtSz-scid/scid mice. J Infect Dis (1995) 172(4):974-82. doi:10.1093/infdis/172.4.974

32. Shultz LD, Schweitzer PA, Christianson SW, Gott B, Schweitzer IB, Tennent B, et al. Multiple defects in innate and adaptive immunologic function in NOD/LtSz-scid mice. J Immunol (1995) 154(1):180-91.

33. Takenaka K, Prasolava TK, Wang JC, Mortin-Toth SM, Khalouei S, Gan OI, et al. Polymorphism in Sirpa modulates engraftment of human 
hematopoietic stem cells. Nat Immunol (2007) 8(12):1313-23. doi:10.1038/ ni1527

34. Ishikawa $\mathrm{F}$, Yasukawa $\mathrm{M}$, Lyons $\mathrm{B}$, Yoshida $\mathrm{S}$, Miyamoto $\mathrm{T}$, Yoshimoto G, et al. Development of functional human blood and immune systems in NOD/SCID/IL2 receptor \{gamma\} chain(null) mice. Blood (2005) 106(5):1565-73. doi:10.1182/blood-2005-02-0516

35. Ito M, Hiramatsu H, Kobayashi K, Suzue K, Kawahata M, Hioki K, et al. NOD/SCID/gamma(c)(null) mouse: an excellent recipient mouse model for engraftment of human cells. Blood (2002) 100(9):3175-82. doi:10.1182/ blood-2001-12-0207

36. Shultz LD, Lyons BL, Burzenski LM, Gott B, Chen X, Chaleff S, et al. Human lymphoid and myeloid cell development in NOD/LtSz-scid IL2R gamma null mice engrafted with mobilized human hemopoietic stem cells. J Immunol (2005) 174(10):6477-89. doi:10.4049/jimmunol.174. 10.6477

37. Audige A, Rochat MA, Li D, Ivic S, Fahrny A, Muller CKS, et al. Longterm leukocyte reconstitution in NSG mice transplanted with human cord blood hematopoietic stem and progenitor cells. BMC Immunol (2017) 18(1): 28. doi:10.1186/s12865-017-0209-9

38. Traggiai E, Chicha L, Mazzucchelli L, Bronz L, Piffaretti JC, Lanzavecchia A, et al. Development of a human adaptive immune system in cord blood cell-transplanted mice. Science (2004) 304(5667):104-7. doi:10.1126/science.1093933

39. Kotloff DB, Bosma MJ, Ruetsch NR. V(D)J recombination in peritoneal B cells of leaky scid mice. J Exp Med (1993) 178(6):1981-94. doi:10.1084/ jem.178.6.1981

40. Garcia JV. In vivo platforms for analysis of HIV persistence and eradication. J Clin Invest (2016) 126(2):424-31. doi:10.1172/JCI80562

41. Rongvaux A, Takizawa H, Strowig T, Willinger T, Eynon EE, Flavell RA, et al. Human hemato-lymphoid system mice: current use and future potential for medicine. Annu Rev Immunol (2013) 31:635-74. doi:10.1146/ annurev-immunol-032712-095921

42. Theocharides AP, Rongvaux A, Fritsch K, Flavell RA, Manz MG. Humanized hemato-lymphoid system mice. Haematologica (2016) 101(1): 5-19. doi:10.3324/haematol.2014.115212

43. Jaiswal S, Pearson T, Friberg H, Shultz LD, Greiner DL, Rothman AL, et al. Dengue virus infection and virus-specific HLA-A2 restricted immune responses in humanized NOD-scid IL2rgammanull mice. PLoS One (2009) 4(10):e7251. doi:10.1371/journal.pone.0007251

44. Shultz LD, Saito Y, Najima Y, Tanaka S, Ochi T, Tomizawa M, et al. Generation of functional human T-cell subsets with HLA-restricted immune responses in HLA class I expressing NOD/SCID/IL2r gamma(null) humanized mice. Proc Natl Acad Sci U S A (2010) 107(29):13022-7. doi:10.1073/ pnas. 1000475107

45. Strowig T, Gurer C, Ploss A, Liu YF, Arrey F, Sashihara J, et al. Priming of protective $\mathrm{T}$ cell responses against virus-induced tumors in mice with human immune system components. JExp Med (2009) 206(6):1423-34. doi:10.1084/jem.20081720

46. Danner R, Chaudhari SN, Rosenberger J, Surls J, Richie TL, Brumeanu TD, et al. Expression of HLA class II molecules in humanized NOD.Rag1KO.IL2RgcKO mice is critical for development and function of human T and B cells. PLoS One (2011) 6(5):e19826. doi:10.1371/journal. pone. 0019826

47. Majji S, Wijayalath W, Shashikumar S, Pow-Sang L, Villasante E, Brumeanu TD, et al. Differential effect of HLA class-I versus class-II transgenes on human $\mathrm{T}$ and $\mathrm{B}$ cell reconstitution and function in NRG mice. Sci Rep (2016) 6:28093. doi:10.1038/srep28093

48. Suzuki M, Takahashi T, Katano I, Ito R, Ito M, Harigae H, et al. Induction of human humoral immune responses in a novel HLA-DR-expressing transgenic NOD/Shi-scid/gammacnull mouse. Int Immunol (2012) 24(4): 243-52. doi:10.1093/intimm/dxs045

49. Lan P, Tonomura N, Shimizu A, Wang S, Yang YG. Reconstitution of a functional human immune system in immunodeficient mice through combined human fetal thymus/liver and $\mathrm{CD} 34+$ cell transplantation. Blood (2006) 108(2):487-92. doi:10.1182/blood-2005-11-4388

50. Melkus MW, Estes JD, Padgett-Thomas A, Gatlin J, Denton PW, Othieno FA, et al. Humanized mice mount specific adaptive and innate immune responses to EBV and TSST-1. Nat Med (2006) 12(11):1316-22. doi: $10.1038 / \mathrm{nm} 1431$
51. Chen Q, Khoury M, Chen J. Expression of human cytokines dramatically improves reconstitution of specific human-blood lineage cells in humanized mice. Proc Natl Acad Sci U S A (2009) 106(51):21783-8. doi:10.1073/ pnas.0912274106

52. Hu Z, Van Rooijen N, Yang YG. Macrophages prevent human red blood cell reconstitution in immunodeficient mice. Blood (2011) 118(22):5938-46. doi:10.1182/blood-2010-11-321414

53. Hu Z, Yang YG. Full reconstitution of human platelets in humanized mice after macrophage depletion. Blood (2012) 120(8):1713-6. doi:10.1182/blood2012-01-407890

54. Coughlan AM, Freeley SJ, Robson MG. Humanised mice have functional human neutrophils. J Immunol Methods (2012) 385(1-2):96-104. doi:10.1016/ j.jim.2012.08.005

55. Doshi M, Koyanagi M, Nakahara M, Saeki K, Saeki K, Yuo A. Identification of human neutrophils during experimentally induced inflammation in mice with transplanted CD34+ cells from human umbilical cord blood. Int J Hematol (2006) 84(3):231-7. doi:10.1532/IJH97.06040

56. Tanaka S, Saito Y, Kunisawa J, Kurashima Y, Wake T, Suzuki N, et al. Development of mature and functional human myeloid subsets in hematopoietic stem cell-engrafted NOD/SCID/IL2rgammaKO mice. J Immunol (2012) 188(12):6145-55. doi:10.4049/jimmunol.1103660

57. Gille C, Orlikowsky TW, Spring B, Hartwig UF, Wilhelm A, Wirth A, et al. Monocytes derived from humanized neonatal NOD/SCID/ IL2Rgamma(null) mice are phenotypically immature and exhibit functional impairments. Hum Immunol (2012) 73(4):346-54. doi:10.1016/j. humimm.2012.01.006

58. Huntington ND, Legrand N, Alves NL, Jaron B, Weijer K, Plet A, et al. IL-15 trans-presentation promotes human NK cell development and differentiation in vivo. J Exp Med (2009) 206(1):25-34. doi:10.1084/jem. 20082013

59. Strowig T, Chijioke O, Carrega P, Arrey F, Meixlsperger S, Ramer PC, et al. Human NK cells of mice with reconstituted human immune system components require preactivation to acquire functional competence. Blood (2010) 116(20):4158-67. doi:10.1182/blood-2010-02-270678

60. Rathinam C, Poueymirou WT, Rojas J, Murphy AJ, Valenzuela DM, Yancopoulos GD, et al. Efficient differentiation and function of human macrophages in humanized CSF-1 mice. Blood (2011) 118(11):3119-28. doi:10.1182/blood-2010-12-326926

61. Rongvaux A, Willinger T, Martinek J, Strowig T, Gearty SV, Teichmann LL, et al. Development and function of human innate immune cells in a humanized mouse model. Nat Biotechnol (2014) 32(4):364-72. doi: $10.1038 /$ nbt. 2858

62. Rongvaux A, Willinger T, Takizawa $\mathrm{H}$, Rathinam C, Auerbach W, Murphy AJ, et al. Human thrombopoietin knockin mice efficiently support human hematopoiesis in vivo. Proc Natl Acad Sci U S A (2011) 108(6): 2378-83. doi:10.1073/pnas.1019524108

63. Willinger T, Rongvaux A, Takizawa H, Yancopoulos GD, Valenzuela DM, Murphy AJ, et al. Human IL-3/GM-CSF knock-in mice support human alveolar macrophage development and human immune responses in the lung. Proc Natl Acad Sci U S A (2011) 108(6):2390-5. doi:10.1073/pnas. 1019682108

64. Landel CP, Dunlap J, Patton JB, Manser T. A germline-competent embryonic stem cell line from NOD.Cg-Prkdc (scid) Il2rg (tm1Wjl)/SzJ (NSG) mice. Transgenic Res (2013) 22(1):179-85. doi:10.1007/s11248-0129629-8

65. Billerbeck E, Barry WT, Mu K, Dorner M, Rice CM, Ploss A. Development of human $\mathrm{CD} 4+\mathrm{FoxP} 3+$ regulatory $\mathrm{T}$ cells in human stem cell factor-, granulocyte-macrophage colony-stimulating factor-, and interleukin-3expressing NOD-SCID IL2Rgamma(null) humanized mice. Blood (2011) 117(11):3076-86. doi:10.1182/blood-2010-08-301507

66. Brehm MA, Racki WJ, Leif J, Burzenski L, Hosur V, Wetmore A, et al. Engraftment of human HSCs in nonirradiated newborn NOD-scid IL2rgamma null mice is enhanced by transgenic expression of membrane-bound human SCF. Blood (2012) 119(12):2778-88. doi:10.1182/ blood-2011-05-353243

67. Coughlan AM, Harmon C, Whelan S, O'Brien EC, O'Reilly VP, Crotty P, et al. Myeloid engraftment in humanized mice: impact of granulocyte-colony stimulating factor treatment and transgenic mouse strain. Stem Cells Dev (2016) 25(7):530-41. doi:10.1089/scd.2015.0289 
68. Wunderlich M, Chou FS, Link KA, Mizukawa B, Perry RL, Carroll M, et al. AML xenograft efficiency is significantly improved in NOD/SCIDIL2RG mice constitutively expressing human SCF, GM-CSF and IL-3. Leukemia (2010) 24(10):1785-8. doi:10.1038/leu.2010.158

69. Bhatt S, Gething PW, Brady OJ, Messina JP, Farlow AW, Moyes CL, et al. The global distribution and burden of dengue. Nature (2013) 496 (7446):504-7. doi:10.1038/nature12060

70. Simmons CP, Farrar JJ, Nguyen V, Wills B. Dengue. N Engl J Med (2012) 366(15):1423-32. doi:10.1056/NEJMra1110265

71. Bente DA, Melkus MW, Garcia JV, Rico-Hesse R. Dengue fever in humanized NOD/SCID mice. J Virol (2005) 79(21):13797-9. doi:10.1128/ JVI.79.21.13797-13799.2005

72. Mota J, Rico-Hesse R. Humanized mice show clinical signs of dengue fever according to infecting virus genotype. J Virol (2009) 83(17):8638-45. doi:10.1128/JVI.00581-09

73. Mota J, Rico-Hesse R. Dengue virus tropism in humanized mice recapitulates human dengue fever. PLoS One (2011) 6(6):e20762. doi:10.1371/ journal.pone. 0020762

74. Sridharan A, Chen Q, Tang KF, Ooi EE, Hibberd ML, Chen J. Inhibition of megakaryocyte development in the bone marrow underlies dengue virus-induced thrombocytopenia in humanized mice. J Virol (2013) 87(21):11648-58. doi:10.1128/JVI.01156-13

75. Balsitis SJ, Coloma J, Castro G, Alava A, Flores D, McKerrow JH, et al. Tropism of dengue virus in mice and humans defined by viral nonstructural protein 3-specific immunostaining. Am J Trop Med Hyg (2009) 80(3):416-24. doi:10.4269/aitmh.2009.80.416

76. Cox J, Mota J, Sukupolvi-Petty S, Diamond MS, Rico-Hesse R. Mosquito bite delivery of dengue virus enhances immunogenicity and pathogenesis in humanized mice. J Virol (2012) 86(14):7637-49. doi:10.1128/ JVI.00534-12

77. Malavige GN, Ogg GS. Pathogenesis of vascular leak in dengue virus infection. Immunology (2017) 151:261-9. doi:10.1111/imm.12748

78. Kuruvilla JG, Troyer RM, Devi S, Akkina R. Dengue virus infection and immune response in humanized RAG2(-/-)gamma(c)(-/-) (RAG-hu) mice. Virology (2007) 369(1):143-52. doi:10.1016/j.virol.2007.06.005

79. Costa VV, Ye W, Chen Q, Teixeira MM, Preiser P, Ooi EE, et al. Dengue virus-infected dendritic cells, but not monocytes, activate natural killer cells through a contact-dependent mechanism involving adhesion molecules. mBio (2017) 8(4):e741-717. doi:10.1128/mBio.00741-17

80. Jaiswal S, Pazoles P, Woda M, Shultz LD, Greiner DL, Brehm MA, et al. Enhanced humoral and HLA-A2-restricted dengue virus-specific T-cell responses in humanized BLT NSG mice. Immunology (2012) 136(3): 334-43. doi:10.1111/j.1365-2567.2012.03585.x

81. Jaiswal S, Smith K, Ramirez A, Woda M, Pazoles P, Shultz LD, et al. Dengue virus infection induces broadly cross-reactive human IgM antibodies that recognize intact virions in humanized BLT-NSG mice. Exp Biol Med (Maywood) (2015) 240(1):67-78. doi:10.1177/1535370214546273

82. Jangalwe S, Shultz LD, Mathew A, Brehm MA. Improved B cell development in humanized NOD-scid IL2Rgammanull mice transgenically expressing human stem cell factor, granulocyte-macrophage colony-stimulating factor and interleukin-3. Immun Inflamm Dis (2016) 4(4):427-40. doi:10.1002/ iid 3.124

83. Cui L, Hou J, Fang J, Lee YH, Costa VV, Wong LH, et al. Serum metabolomics investigation of humanized mouse model with dengue infection. J Virol (2017) 91:e00386-17. doi:10.1128/JVI.00386-17

84. Frias-Staheli N, Dorner M, Marukian S, Billerbeck E, Labitt RN, Rice CM, et al. Utility of humanized BLT mice for analysis of dengue virus infection and antiviral drug testing. J Virol (2014) 88(4):2205-18. doi:10.1128/JVI.03085-13

85. Robinson LN, Tharakaraman K, Rowley KJ, Costa VV, Chan KR, Wong $\mathrm{YH}$, et al. Structure-guided design of an anti-dengue antibody directed to a non-immunodominant epitope. Cell (2015) 162(3):493-504. doi:10.1016/j.cell.2015.06.057

86. Baize S, Pannetier D, Oestereich L, Rieger T, Koivogui L, Magassouba N, et al. Emergence of Zaire Ebola virus disease in Guinea. N Engl J Med (2014) 371(15):1418-25. doi:10.1056/NEJMoa1404505

87. Rougeron V, Feldmann H, Grard G, Becker S, Leroy EM. Ebola and Marburg haemorrhagic fever. JClin Virol (2015) 64:111-9. doi:10.1016/j. jcv.2015.01.014
88. Olival KJ, Hayman DT. Filoviruses in bats: current knowledge and future directions. Viruses (2014) 6(4):1759-88. doi:10.3390/v6041759

89. Feldmann H, Geisbert TW. Ebola haemorrhagic fever. Lancet (2011) 377(9768):849-62. doi:10.1016/S0140-6736(10)60667-8

90. Prescott JB, Marzi A, Safronetz D, Robertson SJ, Feldmann H, Best SM. Immunobiology of Ebola and Lassa virus infections. Nat Rev Immunol (2017) 17(3):195-207. doi:10.1038/nri.2016.138

91. Ruibal P, Oestereich L, Ludtke A, Becker-Ziaja B, Wozniak DM, Kerber R, et al. Unique human immune signature of Ebola virus disease in Guinea. Nature (2016) 533(7601):100-4. doi:10.1038/nature17949

92. Dahlke C, Lunemann S, Kasonta R, Kreuels B, Schmiedel S, Ly ML, et al. Comprehensive characterization of cellular immune responses following Ebola virus infection. J Infect Dis (2017) 215(2):287-92. doi:10.1093/ infdis/jiw508

93. Yamaoka S, Banadyga L, Bray M, Ebihara H. Small animal models for studying filovirus pathogenesis. Curr Top Microbiol Immunol (2017). doi:10.1007/82_2017_9

94. Bird BH, Spengler JR, Chakrabarti AK, Khristova ML, Sealy TK, Coleman-McCray JD, et al. Humanized mouse model of Ebola virus disease mimics the immune responses in human disease. J Infect Dis (2016) 213(5):703-11. doi:10.1093/infdis/jiv538

95. Spengler JR, Lavender KJ, Martellaro C, Carmody A, Kurth A, Keck JG, et al. Ebola virus replication and disease without immunopathology in mice expressing transgenes to support human myeloid and lymphoid cell engraftment. J Infect Dis (2016) 214(Suppl 3):S308-18. doi:10.1093/ infdis/jiw248

96. Ludtke A, Oestereich L, Ruibal P, Wurr S, Pallasch E, Bockholt S, et al. Ebola virus disease in mice with transplanted human hematopoietic stem cells. J Virol (2015) 89(8):4700-4. doi:10.1128/JVI.03546-14

97. Elliott RM, Schmaljohn CS. Bunyaviridae. In: Knipe DM, Howley PM, editors. Fields Virology. Philadelphia, USA: Lippincott Williams \& Wilkins (2014). p. 1244-82.

98. Bente DA, Forrester NL, Watts DM, McAuley AJ, Whitehouse CA, Bray M. Crimean-Congo hemorrhagic fever: history, epidemiology, pathogenesis, clinical syndrome and genetic diversity. Antiviral Res (2013) 100(1):159-89. doi:10.1016/j.antiviral.2013.07.006

99. Spengler JR, Keating MK, McElroy AK, Zivcec M, Coleman-McCray JD, Harmon JR, et al. Crimean-Congo hemorrhagic fever in humanized mice reveals glial cells as primary targets of neurological infection. J Infect Dis (2017) jix215. doi:10.1093/infdis/jix215

100. Kruger DH, Figueiredo LT, Song JW, Klempa B. Hantaviruses globally emerging pathogens. J Clin Virol (2015) 64:128-36. doi:10.1016/ j.jcv.2014.08.033

101. Jonsson CB, Figueiredo LT, Vapalahti O. A global perspective on hantavirus ecology, epidemiology, and disease. Clin Microbiol Rev (2010) 23(2): 412-41. doi:10.1128/CMR.00062-09

102. Clement J, Maes P, Van Ranst M. Hemorrhagic fever with renal syndrome in the new, and hantavirus pulmonary syndrome in the old world: paradi(se)gm lost or regained? Virus Res (2014) 187:55-8. doi:10.1016/j. virusres.2013.12.036

103. Schonrich G, Rang A, Lutteke N, Raftery MJ, Charbonnel N, Ulrich RG. Hantavirus-induced immunity in rodent reservoirs and humans. Immunol Rev (2008) 225:163-89. doi:10.1111/j.1600-065X.2008.00694.x

104. Vaheri A, Strandin T, Hepojoki J, Sironen T, Henttonen H, Makela S, et al. Uncovering the mysteries of hantavirus infections. Nat Rev Microbiol (2013) 11(8):539-50. doi:10.1038/nrmicro3066

105. Charbonnel N, Pages $M$, Sironen $T$, Henttonen $H$, Vapalahti $O$, Mustonen J, et al. Immunogenetic factors affecting susceptibility of humans and rodents to hantaviruses and the clinical course of hantaviral disease in humans. Viruses (2014) 6(5):2214-41. doi:10.3390/v6052214

106. Koma T, Yoshimatsu K, Nagata N, Sato Y, Shimizu K, Yasuda SP, et al. Neutrophil depletion suppresses pulmonary vascular hyperpermeability and occurrence of pulmonary edema caused by hantavirus infection in C.B-17 SCID mice. J Virol (2014) 88(13):7178-88. doi:10.1128/JVI. 00254-14

107. Lalwani P, Raftery MJ, Kobak L, Rang A, Giese T, Matthaei M, et al. Hantaviral mechanisms driving HLA class I antigen presentation require both RIG-I and TRIF. Eur J Immunol (2013) 43(10):2566-76. doi:10.1002/ eji.201243066 
108. Markotic A, Hensley L, Daddario K, Spik K, Anderson K, Schmaljohn C. Pathogenic hantaviruses elicit different immunoreactions in THP-1 cells and primary monocytes and induce differentiation of human monocytes to dendritic-like cells. Coll Antropol (2007) 31(4):1159-67. doi:10.0000/ PMID18217475

109. Schonrich G, Kruger DH, Raftery MJ. Hantavirus-induced disruption of the endothelial barrier: neutrophils are on the payroll. Front Microbiol (2015) 6:222. doi:10.3389/fmicb.2015.00222

110. Raftery MJ, Lalwani P, Krautkrmer E, Peters T, Scharffetter-Kochanek K, Kruger R, et al. beta2 integrin mediates hantavirus-induced release of neutrophil extracellular traps. J Exp Med (2014) 211(7):1485-97. doi:10.1084/ jem.20131092

111. Schonrich G, Raftery MJ. Neutrophil extracellular traps go viral. Front Immunol (2016) 7:366. doi:10.3389/fimmu.2016.00366

112. Kobak L, Raftery MJ, Voigt S, Kuhl AA, Kilic E, Kurth A, et al. Hantavirusinduced pathogenesis in mice with a humanized immune system. J Gen Virol (2015) 96(Pt 6):1258-63. doi:10.1099/vir.0.000087

113. Lutteke N, Raftery MJ, Lalwani P, Lee MH, Giese T, Voigt S, et al. Switch to high-level virus replication and HLA class I upregulation in differentiating megakaryocytic cells after infection with pathogenic hantavirus. Virology (2010) 405(1):70-80. doi:10.1016/j.virol.2010.05.028
114. Connolly-Andersen AM, Sundberg E, Ahlm C, Hultdin J, Baudin M, Larsson J, et al. Increased thrombopoiesis and platelet activation in hantavirus-infected patients. J Infect Dis (2015) 212(7):1061-9. doi:10.1093/infdis/ jiv161

115. Akkina R. Human immune responses and potential for vaccine assessment in humanized mice. Curr Opin Immunol (2013) 25(3):403-9. doi:10.1016/j. coi.2013.03.009

116. Akkina R. Humanized mice for studying human immune responses and generating human monoclonal antibodies. Microbiol Spectr (2014) 2(2):1-12. doi:10.1128/microbiolspec.AID-0003-2012

Conflict of Interest Statement: The authors declare that the research was conducted in the absence of any commercial or financial relationships that could be construed as a potential conflict of interest.

Copyright (C) 2017 Schönrich and Raftery. This is an open-access article distributed under the terms of the Creative Commons Attribution License (CC BY). The use, distribution or reproduction in other forums is permitted, provided the original author(s) or licensor are credited and that the original publication in this journal is cited, in accordance with accepted academic practice. No use, distribution or reproduction is permitted which does not comply with these terms. 